\title{
EURÍPEDES: OS CICLOPES E A NATUREZA
}

Maria Regina Candido

Universidade Federal do Rio de Janeiro

\begin{abstract}
REsumo: A Sicilia despertava o interesse de outras civilizações como a cartaginense $e$ a grega devido a riqueza da região. Entretanto, o acesso a esta riqueza era impedido pelos nativos que repeliam violentamente 0 assédio d região. No imaginário grego, a reação dos nativos asseme/hava-se ds atividades do seu vulcão Etna, que se manifestava sem controle, inóspido e selvagem. Configurando uma reação de total subordinação as leis da natureza e uma ação de alteridade do mundo de normas do grego civilizado. Assim, os Ciclopes apresentam ao ateniense o outro-diferente e ao mesmo tempo evidencia a relação entre Atenas como centro civilizado e a Sicília como região periférica do mundo civilizado, espaço do outro-diferente em estado de barbárie.
\end{abstract}

Palavaas-chave: Euripes, 0 Ciclope

No drama satírico 0 Ciclope, o poeta Eurípides deixa transparecer como 0 cidadão ateniense do século $\mathrm{V}$ concebia a existência de hábitos e costumes estrangeiros ou bárbaros, partindo de uma visão cultural de si mesmo.

Desde a antiguidade arcaica, a Sicilia despertava interesse de diversos povos, entre eles os gregos. No entanto, 0 acesso à esta riqueza da região, neste período, era impedido pelos nativos que repeliam violentamente qualquer assédio a ilha e ao seu interior. No imaginário grego, a reação dos nativos era representada simbolicamente, e de modo análogo, às atividades do seu vulcão Etna. Ou seja, eram reações sem controle e totalmente subordinadas às leis da natureza.

Mesmo após o seu período de colonização, o interesse e o receio por esta região permaneciam presentes na sociedade poliade do século V. Estes são evidenciados no momento da organização da expedição e acreditava que seus cidadãos e aliados seriam capazes de se submeter a Sićlia (Tucídides, 1988, VI, 2). Entretanto, tinha em Nícias o seu principal opositor e que alertava aos atenienses que a conquista da ilha seria um empreendimento arriscado e diffcil (Diodorus Sículus, 1976, V, 84-2).

Este antagonismo Atenas-Sicilia e culto selvagem que a sociedade ateniense deixa transparecer, pode ser evidenciado no drama satírico 0 Ciclope, escrito no período de 421 a 416 por Eurípides (Rocha Pereira, 1987: 373). Neste drama, podemos constatar como o cidadão ateniense, conhecedor da existênxia de culturas diversas - através das narrativas de Herôdoto - construia a imagem do outro a partir de uma visão etnocêntrica, onde o homem grego seria o parâmetro de um modelo de civilização.

Para os atenienses, o mundo estava permeado de povos semelhantes e povos diferentes, levando-os a traçar a dualidade do grego civilizado e 0 outrodiferente, bárbaro e uma série de nuances como troglodita ou antropófago, 
categorias que variavam a medida que se distanciavam espacialmente de Atenas. Sendo, portanto, 0 ateniense considerado o modelo ideal de cidadão que se deveria ser conhecido e imitado. Isto porque, para o cidadão, a Hélade estaria no centro do mundo e nas regiōes não civilizadas, em estado de barbárie.

Dentro desta concepção do outro, podemos situar a região da Sicília, mesmo com a sua área ocidental colonizada pelo grego. 0 lado oriental, segundo Nícias, seria uma região inóspida, longínqua, espaço de predomínio do outro: região de costumes e hábitos diferentes e de populações estrangeiras e hostis (Tucidides, 1988, VI. 23). A Siclilia seria uma região periférica em relação a civilização grega e permeada de diversos obstáculos a serem transpassados. No entanto, Tucídides nos informa que durante 0 inverno os atenienses navegavam para a ilha com uma frota a fim de conquistá-la, ignorando a grande extensão da itha e o número considerável de seus habitantes (Tucidides, 1988, VI.1).

0 grego tinha conhecimento de que a ilha havia sido colonizada desde 0 VIII século e ocupada por diversos grupos gregos e bárbaros (Tucídides, 1988 ,VI.23), como os sícolos oriundos da Itália, os cartaginenses localizados na região costeira do norte da África, além da população nativa, entre eles os ciclopes, fixados nas regiõs rochosas. Nestas montanhas constata-se a presença de minérios de ferro, níquel e sílica formados pela altíssima quantidade de calor. A alta temperatura produz a fusão das rochas nas camadas internas da montanha (Revista Ecológica, no.5, 1991). No período clássico, Tucídides registrou em sua obra a crença dos habitantes daquela região que acreditavam que a ilha fosse morada do deus Hefesto com sua forja, pois saia dela fogo à noite e fumaça de dia (Tucídides, 1988, III. 88).

0 poeta faz sua releitura de narrativa do mito dos ciclopes, dando-Ihes uma nova interpretação, onde estes seriam seres enormes, gigantes como as montanhas e possuidores de um olho so na fronte. Eles urram e lançam pedras, demonstrando a enorme força física (Jacob, 1991: 19): Diante desta descrição, somos inclinados a pensar que os ciclopes seriam uma personificação simbólica das violentas atividades do vulcão Etna. Esta concepção se reforça ao observarmos a passagem em Odisseu se refere ao ciclope Polifemo "...habitas as profundidades da terra (...) ao pé do Etna, a rocha que destila fogo" (Eurípides, 1983, v. 110).

Os mitógrafos acrescentam mais duas versões referentes aos ciclopes: os gigantes Brontes, Steropes e Argos seriam filhos de Gaia e Uranos: conhecedores do segredo da metalurgia, eles teriam criado o raio e 0 deram a Zeus que, com essa ajuda, consegue vencer a luta contra os Titãs (Zaidman, 1989: 173). A outra referência do mito vem da região da Ásia Menor, onde os ciclopes seriam construtores de monumentos e grandes muros. Eles teriam ajudado o herói Perseu a fortificar Argos, em pouco espaço de tempo e sendo por isso chamados de gigantes de cem braços (Grimal, 1951).

No drama, Eurípides apresenta o ciclope polifermo como "...um deus, decendente de deuses" (Eurípides, 1983, v. 230), filho de Poseidon, soberano deus do mar com a ninfa Toosa (Eurípides, 1983, v. 20). 0 herói Ossideu, por uma trama da natureza, teve as suas embarcações avariadas pelos ventos marinhos no litoral da Sicília (Eurípides, 1983, v.105). Ele consegue salvar-se junto a seus conmpanheiros e entra em contato com a região dos nativos da ilha. 0 modo de viver do outro passa a ser apreendido visualmente por Odisseu ao perceber que os seres habitantes da região vivem isolados enter si e sem cidades cercadas por 
muralhas. Isto porque a noção de proteção liga-se a um aspecto cultural (Garlan, 1991, p. 119). A existência de muralha é essencialmente reveladora de uma natureza humanizada e a sua ausência evidencia, de início, a alteridade do gênero de vida e de costumes destes nativos gigantes em relação ao sistema poliade do cidadão.

Diante deste quadro; 0 grego sente-se superior por ser um cidadão poliade. Esta constatação pode ser demostrada na seguinte citação: "...sou Odisseu de ítaca, filho de Laerte (...) senhor das terras de Cafaténios" (Eurípides, 1983, v. 100). Esta passagem reafirma o caráter etnocentrico do grego, do eu civilizado do outro diferente. No imaginário grego o cidadão está situado entre os deuses e os seres selvagens. Tanto os deuses quanto os deuses quanto os seres selvagens são seres divinos inseridos na categoria do outro-diferente: os deuses seriam mais poderosos e mais sábios que os mortais e não estariam subordinados às imperfeições naturais de um mortal, tais como a idade, as dores e a morte (Sissa; Detiene, 1990, p. 43). Os seres selvagens estariam no espaço da caça, onde a natureza permanecera intocável, freqüentada por divindades específicas como fauna e flora exóticas e seres de hábitos e costumes diferentes (Jacob, 1991, p. 52).

No drama, a comunicação entre estes espaços distintos precisava ser estabelecida. Sendo assim, o poeta faz uso do recurso de um ser intermediário, no caso os Sátiros e Silenos, seres que acompanham o deus Dionisos em seu cortejo festivo (Eurípides, 1983, v. 25). Os Sátiros seriam uma referência comhecida do grego e funcionaria como um canal de informações a Odisseu, a fim de evidenciar o comportamento dos ciclopes, isto seria possível porque Polifermo havia aprisionado os Sátiros supreende 0 deus Odisseu, demonstrando a alteridade absoluta (Zumtnor, 1980, p. 35-36) a partir das ausências, como o não conhecimento das leis e das instituições pollades, pois os ciclopes vivem isolados e não participam de assembléias. 0 não conhecimento da agricultura denota, em primeiro lugar, a ausência de uma sociedade com o status de civilizada e, em segundo lugar, o desconhecimento da vida sedentária.

Como seres nômades, os ciclopes não desenvolviam o hábito do cultivo, vivendo do que nasce espontaneamente na natureza, sem uso de arados e sementes (Odisséia, v. 110), alimentando-se de leite, queijo e carne do rebanho (Eurípides, v. 115). 0 fato de não cultivarem a terra evidencia que os ciclopes desconhecem o pão e o vinho, alimentos que são fruto do trabalho humano e uma referência de um mundo civilizado. 0 cidadão na Grécia entendia que a vida civilizada ocorre entre os seus semelhantes que falam a mesma língua, utilizam as mesmas táticas de guerra, comem da mesma maneira alimentos cozidos e oferecem sacrificios aos mesmos deuses (Sissa; Detienne, 1990, p. 32). Os deuses recebem os animais em sacrifício, onde os ossos são separados e cobertos com gorduras e se colocando ao redor pedaços de carne crua (lliada, v.459-461) que são oferecidas sob forma de fumaças que seriam imanações perfumadas, pois os deuses, através do sacrifício animal, o recebem sob a forma de odor (Sissa; Detienne, 1990, p. 86-92). 0 ritual é seguido por preces que estabelecem o contato entre os mortais e os deuses. Aos homens, na seqüência da cerimônia, é permitido assar o restante da carne e partilhá-la entre si como alimento. Isto representa um comportamento social de contato com os deuses e ao mesmo tempo reafirma as relações sociais estabelecidas entre os homens experimentam 0 ato de conviver com os amigos, onde se falam, trocam informações, estabelecem relações de reciprocidade, de hospitalidade e solidariedade. 
Diante destas características comuns aos cidadãos, a maneira de viver dos ciclopes revela 0 quanto estes seres gigantes apresentam um hábito de vida em total inversão ao do homem civilizado. Os ciclopes reafirmam o seu estado de barbárie e antropofagia quando falam que os estrangeiros possuem as carnes mais saborosas e por isto seriam cozidas em um caldeirão (Eurípides, 1993, v. 240). Esta afirmação dos ciclopes sobre suas preferências pela carne humana pode estar relacionada ao fato do gado criado em montanha ter a carne muito dura, sendo, portanto, destinado à produção leiteira; pode estar relacionada também a uma representação simbólica de transição entre o cru e o cozido, ou ainda a conotação simbólica de devorar e desfigurar a cultura podem ser extraídas, através de um estudo mais aprofundado,

Na concepção grega, a antropofagia demonstra ser o estado mais selvagem dos seres, o que causa o mais supremo horror a Odisseu. Polifermo ao alimentar-se de carne semi-crua, demonstra pertencer a um outro espaço social e comete a hybris, a desmedida ao reafirmar não ter receio de Zeus e nem dos demais deuses, pois ele acredita ser mais forte do que todos (Odisséia, IX. 275276). A partir desta colocação de Polifermo, podemos delinear um quadro totalmente oposto em termos de alimentação e da relação com os deuses pelo homem grego. Este se alimenta de pão e de vinho, presta libações aos deuses e comem carne de gado cozida, sacrificada aos deuses. Os ciclopes evidenciam a total alteridade ao mundo civilizado ao viverem isolados em cavernas naturais e não em oikos, não cultivarem os deuses, viverem do que nasce expontaneamente da terra $e$ praticarem a antropofagia.

Diante destas evidências, 0 grego traça mentalmente 0 limite em que se encontra os ciclopes: estado de regressão à bestialidade. 0 desrespeito aos deuses e aos homens é evidenciado no desconhecimento da lei- da hospitalidade, demonstrando nos ciclopes toda a falha e diferença em relação à sociedade poliade, como podemos observar na passagem em que Odisseu nos revela "...existe um costume entre os mortais (...) de acolher como suplicantes aos que sobrem os embates do mar, entregando-Ihes 0 dom da hospitalidade e socorrendo-Ihes..." (Eurípides, 1983, v. 300). Polifermo, entretanto evidencia um comportamento diferente, porque ele "...sacrificas teus hóspedes que vêm como suplicantes em refúgio a tua morada, dando a ti um banquete com suas carnes cozidas, despedaçando-as com seus dentes malditos e mastigando-as quentes, recém tiradas da brasa..." (Eurípides, 1983, v. 370).

Odisseu, como herói grego, se coloca cada vez mais em que um patamar superior, baseado na imagem de si mesmo e na perspectiva em inferioridade do outro. 0 ciclope Polifermo, com toda a sua enorme força física, é derrotado pela astúcia e pela palavra. Odisseu conhece a força da palavra e da argumentação, instrumentos fundamentais dos participantes das assembléias em defesa de suas idéias. Foi através deste mesmo caminho que Alciblades convenceu os atenienses a organizarem uma expedição militar à Sicilia em ajuda aos egesteus, povos da região envolvidos em um conflito com propositos de certo direito matrimonial e de disputa de terra (Tucídides, 1988, VI. 6). Alcibíades, partindo de uma visão etnocêntrica, alertava as facilidades da vitória, visto que a região era habitada por uma população heterogênea, confusa, sem unidade e não representando um "agir com propósito comum" (Tucícides, 1988, VI. 17). 
Pelo poder da palavra, o grego persuade e expõe suas idéias aos seus pares. Isto, porque ele integra uma sociedade civilizada, onde a força física para convencer perdeu espaço para a força do saber falar, saber dizer. Odisseu convence o gigante Polifermo a beber o vinho puro (Eurípides, 1983, v. 148) e sem misturá-lo com uma porção de água (Eurípides, 1983, v. 100), o que leva o ciclope ao estado de embriaguez. 0 ato de beber 0 vinho puro e em excesso revela um comportamento não civilizado. A embriaguez do gigante permite a Odisseu e aos seus companheiros a empreenderem uma fuga pelo mar da Sicilia, após cegar o ciclope.

0 gigante Polifermo foi vencido pelo desconhecimento da cultura do mundo poliade, a sua derrota o seu estado de total subordinação as leis da natureza: sem controle e sem regras. A barbárie e a antropofagia são traduzidas ao código do cidadão ateniense como um estado de domínio do pathos - da emoção; configurando um estado de serenidade ao mundo do grego civilizado.

Resume: La Sicile, en raison de leurs richesses, éveillait l'interêt d'autres civilisations comme la cathaginoise et la Grecque. Toutefois, l'acces à ces richesses était enterdit par les natifs, lesquels répoussaient violemment le siege de la région. Dans l'esprit des grecs, la réaction des natifs était semblable aux éruptions de leur volcan, l'Etna, sauvage et dévastateur. De cette maniere, se configure une réaction de totale subordination aux lois de la nature, ainsi qu'une action d'alterité dans le conjoint de normes du Grec civilisé. Ainsi, les Cyclopes présentent aux atheniens l'autre/différent et au mêne temps, rend évident le rapport entre Athenes comme centre civilisé et la Sicile comme région périphérique du monde civilisé, espace de l'autre/différent en état de barbarie.

\section{BibLIOgRafia}

Documentação textual

DIODOROS SÍCULUS. Library of History. London: Willian Heeinemann, 1976.

EURÍPIDES. Tragédias. Marid: Gredos, 1983.

HOMERO. Odissea. Madrid: Gredos, 1982.

HOMERO. IIfada. Rio de Janeiro: Melhoramentos, s/d.

TUCÍDIDES. História da Guerra do Peloponeso. Brasília: UnB, 1988.

\section{Bibiografia Geral}

BRANDÃO, J. Mitologia Grega. Petrópolis: Vozes, 1991.

GARLAN, Y. Guerra e Economia na Grécia Antiga. São Paulo: Papirus, 1991.

GRIMAL, P. Dicionário de la Mytologie Grecque et Romaine. Univ. France, 1951.

JACOB, C. Geographie et Ethnografie on Grece Ancienne. Paris: Armand Colin, 1991.

PEREIRA, M. H. R. Estudos da Historia da Cultura. Lisboa: Caloustre Gulbenkian, 1987.

SISSA, G. et MARCEL, D. Os Deuses Gregos. São Paulo: Companhia das Letras, 1990.

ZAIDMAN, L. La Religion Grecque. Paris: Armand Colin, 1989.

ZUMTHOR, P. Parler du Muyen Age. Paris: Editins de Minut, 1980. 